\title{
Recurrent patterns of phylogenetic habitat filtering in woody plant communities across phytogeographically distinct grassland-forest ecotones
}

\author{
V. J. Debastiani ${ }^{1,6}$, S. C. Muller², J. M. Oliveira ${ }^{3}$, F. S. Rocha ${ }^{4}$, M. C. Sestren-Bastos ${ }^{5}$
}

and L. D. S. Duarte 1

${ }_{1}^{1}$ Phylogenetic and Functional Ecology Lab, Universidade Federal do Rio Grande do Sul. Av. Bento Gonçalves 9500 , Porto Alegre, RS 91501-970, Brazil. (www.ufrgs.br/leff)

2 Departamento de Ecologia, Universidade Federal do Rio Grande do Sul, Porto Alegre, Brazil

3 Programa de Pós-Graduação em Biologia, Universidade do Vale do Rio dos Sinos, São Leopoldo, Brazil

${ }^{4}$ Departamento de Fitotecnia, Universidade Federal de Santa Catarina, Florianópolis, Brazil

5 Secretaria Municipal do Meio Ambiente, Porto Alegre, Brazil

${ }^{6}$ Corresponding author: E-mail vanderleidebastiani@yahoo.com.br

Keywords: Community assembly, Edge effect, Phylogenetic structure, Forest expansion, Phylogenetic pool, Phylogenetic diversity.

\begin{abstract}
The phylogenetic relationship among species may influence the mechanisms controlling local community assembly in ecological time. We analyzed the degree of recurrence of phylogenetic structure patterns in woody plant communities distributed along grassland-forest ecotones, across different vegetation types in southern Brazil, and the effect of phylogenetic pool size used to assess such patterns. Species frequency in quadrats distributed along grassland-forest ecotones was surveyed in different phytogeographic regions, where forests tend to expand over grasslands. We used principal coordinates of phylogenetic structure (PCPS) to evaluate the structure within vegetation quadrats divided into three habitat categories: grassland, forest edge and forest interior. Furthermore, phylogenetic structure measures were computed using different phylogenetic pool sizes. Our analyses showed consistent patterns in relation to habitat categories and to different phylogenetic pool sizes. Basal clades of angiosperms were associated with forest areas, while late-divergence clades were associated with grasslands. These results suggest that grasslands act as phylogenetic habitat filters to forest woody species, independently of species composition at each site and the phylogenetic pool. Rosanae and Asteranae act as vanguards of forest expansion over grasslands, while Magnolianae species tend to be restricted to forest. Our results shed light on the organization of ecological systems, providing evidence of recurrent phylogenetic structure patterns in ecotone plant communities at regional scale.
\end{abstract}

Nomenclature: The International Plant Names Index.

Abbreviations: PCPS - Principal Coordinates of Phylogenetic Structure.

\section{Introduction}

One of the main goals of ecology is to decipher the rules determining community assembly patterns from a set of regional species. Understanding how ecological communities are assembled has been a major challenge for community ecologists for a long time (Diamond 1975). Different factors have been evoked to explain community organization, from niche-based (Keddy and Weiher 1999) to dispersal-based mechanisms (Hubbell 2001). Furthermore, the influence of historical and evolutionary factors on community assembly patterns cannot be overlooked (Ricklefs 1987, Webb et al. 2002, Cavender-Bares et al. 2009). Indeed, all these mechanisms are likely to act together to determine community assemblies, difficulting our ability to make generalizations for real communities.
Species are not independent entities in relation to each other, but share a common evolutionary history (Darwin 1859, Felsenstein 1985). In general, it is expected that phylogenetically closely-related species are more similar regarding their ecological traits and ecological demands for reproduction, growth and, consequently, persistence, than more distantly related taxa (Darwin 1859, Burns and Strauss 2011). Phylogenetic affinities among species co-occurring in a community are the net result of their evolutionary histories and their ecological responses to the present environmental conditions (Pillar and Duarte 2010). Ecological processes are based upon phenotypic responses of the organisms related to their environment and to other organisms. For this reason, responses of organisms to the environment largely depend on the genetic information acquired during their evolutionary history. The interplay between evolutionary information and present ecological interactions generate non-random patterns 
of evolutionary relationship among species co-occurring in communities. For this reason, analyzing phylogenetic community patterns is crucial for understanding the mechanisms determining community organization (Webb et al. 2002, Kembel and Hubbell 2006, Cavender-Bares et al. 2009).

The action of environmental filters and/or biotic interactions may determine phylogenetic structure of communities (Webb et al. 2002). Conservatism of ancestral traits in some clades and the appearance of evolutionary novelties in others, allow different clades to occupy different environments (Donoghue 2008, Duarte 2011), which characterizes a phylogenetic habitat filtering (Duarte 2011). Phylogenetic habitat filtering is the limitation that certain clades can find for occupying and persisting in certain habitats while others clades do not. The use of measures addressing clade composition between communities enables the evaluation of how ecological and evolutionary processes interact in present community organization.

Forest edges comprise unique environmental conditions, when compared to surrounding environments, and such environment gradients are likely to have implications in community assembly processes. In vegetation mosaics, composed by grasslands and forests, environmental conditions at forest edges, such as light, temperature and moisture, vary when compared to forest interior (Matlack 1994). For instance, wind disturbance, soil dryness, air temperature and photosynthetic radiation, among other effects, may increase as the distance to forest edges decreases (Kapos 1989). These may result in compositional and structural changes, such as high tree mortality, changes on canopy cover, changes on shrubs and herbs cover, increase on understory density, besides changes in recruitment, seedling mortality and increase of plants that are adapted to disturbance (Laurance et al. 2002, Ries et al. 2004, Harper et al. 2005). Such effects may vary in magnitude and reach different distances from the edge (Harper et al. 2005). Closer to edges, environmental conditions are frequently intermediary when compared to surrounding environments (Ries et al. 2004).

Analysis of phylogenetic community structure in ecotones may help to comprehend the processes that are acting in these systems, especially where one vegetation type tends to advance over another. Most studies addressing edge effects have usually evaluated fragmented landscapes with abrupt edges (Santos et al. 2010), as well as the recolonization of areas that were formerly occupied by forest vegetation (Letcher 2010). On the other hand, edge effects on natural vegetation mosaics, where edges tend to be less abrupt, still lack a deeper assessment (Duarte et al. 2007). The expansion of woody vegetation over natural grasslands is a contemporary phenomenon observed in many parts of the world (Scholes and Archer 1997, Bond and Midgley 2000). Studies have associated woody encroachment with the increment in atmospheric $\mathrm{CO}_{2}$ for the last 200 years (Bond and Midgley 2000). This process has obvious consequences for economic activities, since grassland areas possess high economic value, such as for livestock production. Further, woody plant encroachment on grassland has important implications for biodiversity conservation (Behling and Pillar 2007). In Southern
Brazil, natural vegetation mosaics with forests and grasslands are widespread. These mosaics occur in areas with different forest types and are under the influence of regional climatic variation (IBGE 1986). For this reason, they are regionally diverse in relation to their phytogeographic origin and often show distinct species composition (Leite 2002). There is an increasing tendency for forest vegetation to advance above grasslands (Rambo 1956, Behling 2002) by means of forest advance through the edges (Oliveira and Pillar 2004) or forest patch nucleation over natural grasslands (Duarte et al. 2007). Therefore, woody vegetation gradients from forest interior towards the edge within grassland might be considered as a chronosequence of the forest expansion over grasslands. In other words, the inner region of the forest interior would represent the oldest forest successional stage. Considering this tendency of woody vegetation to advance over grasslands, plants occurring at opener sites could be expected to represent a subset of species from forest interior areas (Laurance et al. 2006).

In this study, we verified the variation in phylogenetic structure of forest woody plant communities along natural ecotones composed by grasslands and forests distributed across different phytogeographic regions in Southern Brazil. Considering a tendency of basal plant clades to keep ecological traits associated with low resistance to dry, sunlit conditions, it is also expected that basal clades are more associated with forest interiors, while clades with more recent diversification are more related to grasslands (Boyce et al. 2009, Brodribb and Feild 2010). Yet, it is expected that variation in phylogenetic composition across ecotones (between sites) will be smaller when compared to species composition variation, since environmental gradient in ecotones would determine a phylogenetic habitat filtering to forest species (Duarte 2011), while species composition between sites would be determined strongly by the phytogeographic origin of each ecotone.

\section{Methods}

\section{Study areas}

We evaluated phylogenetic patterns in woody forest vegetation occurring in mosaics composed by grasslands and forest vegetation representing the three forest formations in natural contact with grasslands in southern Brazil (Leite 2002). The first comprises Mixed forests with Araucaria angustifolia, which is the main forest type in Southern Brazilian plateau and occurs in a pluvial climate without pronounced droughts. Mixed forests are formed by a mixture of tropical and temperate floras with Araucaria angustifolia and Podocarpus lambertii as physiognomically most important species. This forest has also many basal angiosperms (Magnolianae), as Laurales and Drimys (Winteraceae), and several species of Myrtaceae (Leite 2002). The second forest type comprises Seasonal Deciduous forests, which are mainly found in the Northwest of Rio Grande do Sul State. These forests have as physiognomic distinctive characteristic the deciduousness of more than $50 \%$ of species from the overstory. Furthermore, 
Table 1. Sites of vegetation sampling, geographic coordinates, prevailing forest type and sampling of each study, amplitude in maximum number of plots by transect for each environment, and inclusion criterion of individuals. The effort is expressed in number of sampled plots and in parentheses is expressed the number of plots for each it was possible to calculate a phylogenetic measure.

\begin{tabular}{|c|c|c|c|c|c|c|}
\hline Locality & Coordinates & $\begin{array}{l}\text { Type of forest } \\
\text { vegetation }\end{array}$ & $\begin{array}{l}\text { Number of } \\
\text { plots per } \\
\text { habitat }{ }^{\dagger}\end{array}$ & $\begin{array}{l}\text { Inclusion } \\
\text { criterion } \ddagger\end{array}$ & Effort & Source \\
\hline Turvo State Park * & $\begin{array}{l}27^{\circ} 13^{\prime} \mathrm{S} ; \\
53^{\circ} 51^{\prime} \mathrm{W}\end{array}$ & $\begin{array}{l}\text { Seasonal deciduous } \\
\text { forest }\end{array}$ & $5 \mathrm{G} / 5 \mathrm{E} / 5 \mathrm{~F}$ & $\begin{array}{c}\geq 0.1 \mathrm{~m} \mathrm{HEI} \text { and } \\
\leq 5 \mathrm{~cm} \mathrm{DAB}\end{array}$ & $\begin{array}{c}180 \\
(\mathrm{n}=163)\end{array}$ & $\begin{array}{c}\text { F. S. Rocha } \\
\text { (unpublished data) }\end{array}$ \\
\hline Morro Santana * & $\begin{array}{l}30^{\circ} 03^{\prime} \mathrm{S} \\
51^{\circ} 07^{\prime} \mathrm{W}\end{array}$ & $\begin{array}{c}\text { Seasonal } \\
\text { semideciduous forest }\end{array}$ & $21 \mathrm{G} / 9 \mathrm{E} / 9 \mathrm{~F}$ & $\begin{array}{c}\geq 0.1 \mathrm{~m} \mathrm{HEI} \text { and } \\
\leq 5 \mathrm{~cm} \mathrm{DAB}\end{array}$ & $\begin{array}{c}348 \\
(\mathrm{n}=240)\end{array}$ & Müller et al. 2012 \\
\hline $\begin{array}{l}\text { Center for Research } \\
\text { and Conservation of } \\
\text { Nature PRÓ-MATA* }\end{array}$ & $\begin{array}{l}29^{\circ} 28^{\prime} \mathrm{S} \\
50^{\circ} 10^{\prime} \mathrm{W}\end{array}$ & $\begin{array}{l}\text { Mixed forest with } \\
\text { Araucaria }\end{array}$ & $18 \mathrm{G} / 4 \mathrm{E} / 3 \mathrm{~F}$ & $\begin{array}{c}\geq 0.1 \mathrm{~m} \mathrm{HEI} \text { and } \\
\leq 5 \mathrm{~cm} \mathrm{DBH}\end{array}$ & $204(n=58)$ & $\begin{array}{l}\text { L. D. S Duarte and J. } \\
\text { Oliveira (unpublished } \\
\text { data) }\end{array}$ \\
\hline $\begin{array}{l}\text { São Francisco de Paula } \\
\text { National Forest }\end{array}$ & $\begin{array}{l}29^{\circ} 24^{\prime} \mathrm{S} \\
50^{\circ} 22^{\prime} \mathrm{W}\end{array}$ & $\begin{array}{l}\text { Mixed forest with } \\
\text { Araucaria }\end{array}$ & $35 \mathrm{G} / 18 \mathrm{E} / 18 \mathrm{~F}$ & $\begin{aligned} \geq & 0.5 \mathrm{~m} \mathrm{HEI} \text { and } \\
& \leq 5 \mathrm{~cm} \mathrm{DBH}\end{aligned}$ & $211(n=113)$ & This study \\
\hline Eldorado do Sul & $\begin{array}{l}30^{\circ} 05^{\prime} \mathrm{S} \\
51^{\circ} 40^{\prime} \mathrm{W}\end{array}$ & $\begin{array}{c}\text { Seasonal } \\
\text { semideciduous forest }\end{array}$ & $9 \mathrm{G} / 5 \mathrm{E} / 4 \mathrm{~F}$ & $\begin{array}{c}\geq 0.5 \mathrm{~m} \mathrm{HEI} \text { and } \\
\leq 2 \mathrm{~m} \text { HEI }\end{array}$ & $27(n=25)$ & $\begin{array}{l}\text { M. C. Sestren-Bastos } \\
\text { (unpublished data) }\end{array}$ \\
\hline Santana da Boa Vista & $\begin{array}{l}30^{\circ} 46^{\prime} \mathrm{S} \\
53^{\circ} 04^{\prime} \mathrm{W}\end{array}$ & $\begin{array}{c}\text { Seasonal } \\
\text { semideciduous forest }\end{array}$ & $35 \mathrm{G} / 17 \mathrm{E} / 18 \mathrm{~F}$ & $\begin{array}{c}\geq 0.5 \mathrm{~m} \mathrm{HEI} \text { and } \\
\leq 5 \mathrm{~cm} \mathrm{DBH}\end{array}$ & $210(\mathrm{n}=97)$ & This study \\
\hline
\end{tabular}

the climate where these forests occur has two seasons with pronounced thermal variation and intense rainfall, one dry and hot season and another cold and wet season (Leite 2002). The third forest type, Seasonal Semideciduous forests are mainly composed by species of tropical elements, pluvial or seasonal. They are distinguished from seasonal deciduous forests by a lower index of deciduousness in overstory and by the absence of some typical species of deciduous forests such as Apuleia leiocarpa (Leite 2002).

\section{Species composition}

We compiled information on the occurrence (presence/ absence) of forest woody species of angiosperms occurring as young saplings (individuals taller than $50 \mathrm{~cm}$ and with a diameter at breast height, measured at approximately $130 \mathrm{~cm}$ from the ground, smaller than $5 \mathrm{~cm}$ ) in plots distributed along grassland and forest transitions from different vegetation surveys carried out in different sites distributed across the study region (Table 1). Species occurring exclusively in grasslands, such as species from genus Baccharis, were not included in the dataset. These species were excluded because they are not recognized as the main species that take part in the process of forest expantion over grasslands.

Plots were distributed between three habitat categories: the first containing all plots from the grasslands, the second and the third containing the plots located in forest interiors; these latter were divided into two equal-sized categories (edge and forest) (Fig. 1). The edge between forest and grasslands was defined visually by the presence/absence of the last adult tree individual. All individuals considered for further analysis were identified to species level. In all compiled surveys the size of plots was $2.25 \mathrm{~m}^{2}$, with the exception of grasslands plots at Center for Research and Conservation of Nature PRÓ-MATA that measured $2.89 \mathrm{~m}^{2}$.
Moreover, two other sites with no information on vegetation patterns in the ecotones were sampled. One of the sites was the São Francisco de Paula National Forest, composed by Araucaria forest and a small area of native grassland. The second site was located in the municipality of Santana da Boa Vista, in a private property, and composed by mosaics of native grasslands and seasonal semideciduous forests. In both sites, three transects were distributed perpendicularly to the edge in the respective ecotone. In each transect, 70 plots of $2.25 \mathrm{~m}^{2}$ were delimited and distributed continuously along each transect. The same number of plots was distributed in the grasslands and in the forests. Within each plot, all angiosperm species with individuals taller than $50 \mathrm{~cm}$ and with a diameter at breast height smaller than $5 \mathrm{~cm}$ were identified to species level.

Altogether, data from five studies carried out in the ecotones were compiled and two sites were sampled (Table 1, Fig. 1). All plots with less than two species were excluded from the analysis, since this is the minimum sample size required to calculate any phylogenetic measure. A total of 696 plots with two or more woody forest species were included in the analysis, from a total sampling effort of 1180 plots in 34 transects.

Species names and taxonomic categories were standardized by consulting experts and by searching the database of Missouri Botanical Garden (www.tropicos.org). The synonymies were checked based on the Taxonomic Name Resolution Service (tnrs.iplantcollaborative.org).

\section{Phylogenetic community structure}

We built a phylogenetic tree for the species included in our checklist, following the phylogenetic hypothesis proposed by Soltis et al. (2011), based on molecular analysis of 17 genes (nuclear DNA, mitochondrial DNA and plastids), 
Figure 1. Graphical representation of sampling procedure. (a) Localities with vegetation sampling (See Table 1). (b) Site scale: the forest areas correspond to regions in grey and the grasslands the lighter regions. Each circle represents the local scale (one site) with its respective transect. (c) Sampling scheme in each transect.

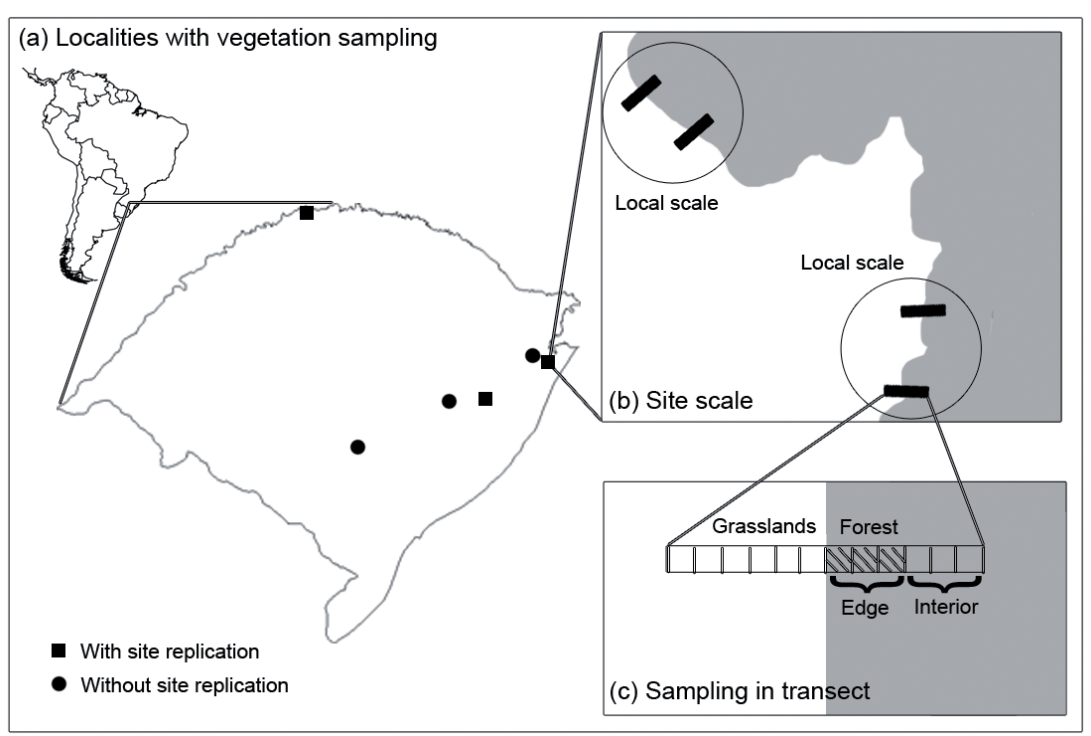

which includes more than 330 families. We used phylogenetic information to establish the evolutionary relationship in taxa higher than or equal to the family level, while within families we considered only taxonomic information. When there was more than a genus in a family, or more than a species in a genus, these were included in a phylogenetic tree as soft polytomies. The sampled families that were not found in Soltis et al. (2011) were inserted in the phylogenetic tree based on the relations proposed by Angiosperm Phylogeny Group (APG 2009). Branch lengths were defined based on clade age estimates proposed by Bell et al. (2010), from molecular analysis for 335 families and using 36 calibration points in the tree, based on fossil records. Since the families sampled by Soltis et al. (2011) and Bell et al. (2010) are not completely compatible, we used the age estimates proposed by Bell et al. (2010) in nodes containing all families related to Soltis et al. (2011). We estimated the age of non-dated nodes by using BLADJ module, from software Phylocom (http://phylodiversity.net/ phylocom/) that evenly interpolates ages in million of years for nodes without age estimate based on dated nodes.

To evaluate the phylogenetic composition of the plots, we defined a matrix of species composition weighted by phylogeny using phylogenetic fuzzy weighting (Pillar and Duarte 2010). This matrix contains the scaled-up phylogenetic relationship among species to the community level and holds the phylogenetic structure of a community. This matrix contains the phylogeny-weighted species composition in a given community, based on its phylogenetic similarity to other species occurring in the metacommunity. This matrix was submitted to principal coordinate analysis (Legendre and Legendre 1998) using square root of the Bray-Curtis index as the dissimilarity measure between communities, generating principal coordinates of phylogenetic structure (PCPS) (Duarte 2011). The first PCPS (those with higher eigenvalues) capture phylogenetic gradients in basal branches, where there is more variation in the age of clades, while the PCPS with lower eigenvalues capture variations toward more terminal branches of the phylogenetic tree. PCPS analysis permits to compare communities regarding their phylogenetic composi- tion (Duarte 2011). Furthermore, each PCPS is associated to phylogenetic gradients encompassing different clades and it is possible to identify which clades are associated to the environmental gradients in the ecotones.

For each plot, we calculated the phylogenetic measure using three different phylogenetic pool sizes defined according to different spatial scales (regional, site and local). At the regional scale, all species found in the whole array of sites were included in the phylogenetic pool. Thus, species from different phytogeographic origins and varying considerably in relation to regional occurrence were included in a single species pool. At the site scale, the phylogenetic pool included all species with a common phytogeographic origin, defined by all species found in each locality. Thus, each sampling site defined an independent phylogenetic pool, which comprised sets of transects located in a homogeneous vegetation type (Fig. 1). Unfortunately, the possibility of analyzing phylogenetic patterns at this scale was not possible for all localities, since in only three of them we had more than one set of transects per site; therefore, analyses at the site scale were carried out only for three localities: Center for Research and Conservation of Nature PRÓ-MATA, Turvo State Park and Morro Santana (Table 1). At the local scale, the phylogenetic pool was defined for each set of transects located within a single sampling site. Local phylogenetic pools permitted the detection of fine-scale phylogenetic structure patterns, which might possibly vary according to local microenvironmental gradients, either within or between sites. The local scale was composed of 11 sites (Table 1 in Appendix 1).

\section{Data analysis}

We evaluated the difference in species composition among the 11 sites included in the dataset with ANOVA with permutation tests (Anderson 2001). The resemblance measure of variation was computed using the Sørensen coefficient, which does not consider double absences of species. As plots located in each transect were not spatially independent from each other, we restricted the permutations in each transect to 
avoid incorporating spatial autocorrelation in the analysis. Each transect was fully permuted between sites, keeping its internal structure, i.e., each sample unit was kept within the transect it belonged to.

We analyzed the variation in the phylogenetic composition of the plots occurring in the three habitat categories (grassland, edge and forest interior) using ANOVA with permutation tests, and independently for the two first PCPS axes (Anderson 2001). ANOVA was performed considering the three species pool sizes. For this, Euclidean distances were used as resemblance measure of variation between pairs of plots. Similarly to the previous analysis, we restricted the permutations of plots within each transect. When ANOVA indicated significant difference between habitat categories, these were compared through an analysis of paired contrasts. The probabilities generated by the contrast analysis were corrected through the Bonferroni method (Sokal and Rohlf 1994). Besides conventional test performed with ANOVA, we used two different null models to support our conclusions. The first null model shuffles the taxa labels of the tips of the tree (species identities) across the phylogenetic tree. The second null model randomizes community data matrix with the independent swap algorithm that maintains both the frequency of occurrence of each species and the species richness observed in each plot (Gotelli and Entsminger 2001). At each randomization the ANOVA was performed and the F-value was used to calculate the significance of each observed F-value through 1000 permutations.

For each phylogenetic pool size (regional, site and local), the scores of the plots in the two first PCPS were plotted in a scatter diagram. From the correlation of each PCPS with the original matrix describing phylogenetic composition of the plots, species belonging to the three superorders that were more representative in the species set (Rosanae, Asteranae and Magnolianae) were projected in a biplot with the scores of the plots. Then, we computed centroids for each array of plots occurring in a given habitat category (grassland, edge and forest interior) and also for the species from each of the three superorders. Thus, for each biplot, representing the different phylogenetic pool sizes, six centroid values were obtained (three habitat categories and, three superorders). Each set of centroid values were adjusted in relation to their position in the biplots, which were built using the different phylogenetic pool sizes using Procrustes analysis (Jackson 1995). This procedure enabled us to evaluate the effect of the phylogenetic pool size on the association between phylogenetic composition and habitat category, as Procrustes analysis minimizes the differences in the sum of squares, $s^{2}$, between two distinct sets of ordination eigenvectors (Jackson 1995). Then we analyzed the congruence in the habitat-superorder association for both the finer phylogenetic scales (local, site) and the regional scale using the Procustes statistic $s^{2}$ (Jackson 1995).

The results of ANOVA and Procrustes analysis were summarized using metanalysis, considering the DerSimonianLaird random effect model. Each site was considered an independent unit (Borenstein et al. 2009). The use of metanalysis allows the combination of results found separately in each site, being then possible to summarize them in only one effect. The metanalysis of ANOVA results summarizes the patterns of phylogenetic variation among habitat categories in a single effect for either site or local phylogenetic pools. In the case of Procrustes results, metanalysis allows to summarize the effect between congruence in habitat-superorder association for either site or local phylogenetic pools, always taking the habitat-superorder association in the regional scale as reference. Effect sizes were obtained by converting F-values from ANOVA into correlation coefficients, taking the square root of the F-value divided by the sum of F-value plus the degrees of freedom. Procrustes $s^{2}$ values were in turn taken directly as correlation coefficients. Then, these so-defined correlations were used to calculate a mean effect for each statistic (ANOVA and Procrustes). The significance of the each mean effect was tested by transforming it in Fisher's $Z$ values (Borenstein et al. 2009).

All analyses were performed in $\mathrm{R}$ statistical environment by using packages picante, ape, vegan, SYNCSA and meta, available at http://cran.r-project.org.

\section{Results}

We recorded a total of 191 species of forest tree angiosperms. Species were distributed in 53 families and seven superorders (Fig. 2). The superorder Rosanae was best represented (113 species) in the dataset, followed by Asteranae (49 species) and Magnolianae (22 species). Lilianae and Caryophyllanae were represented by few species (two and three, respectively), while Proteanae and Santalanae were represented by only one species each. Casearia decandra, Psychotria leiocarpa, Myrciaria cuspidata, Mollinedia elegans and Eugenia uniflora were the most frequent species. However, 25 species were singletons (Table 1 in Appendix 2). The diferences in species composition, among the 11 sites, were statistically significant $(\mathrm{F}=36.871 ; \mathrm{p}<0.001)$, indicating that species composition is someway determined by the phytogeographic origin of each ecotone.

At the regional scale the first PCPS summarized 24.64\% of variation of species composition weighted by phylogeny while the PCPS 2 accounted for $12.18 \%$ of the total variation in phylogenetic composition in the plots. ANOVA of PCPS 1 showed significant differences between habitat categories $(\mathrm{F}=24.852, \mathrm{p}<0.001)$; plots in the grassland differed from those located at forest edges and interior, while plots at the edge did not differ from the forest interior habitat (Fig. 3). Furthermore, for this scale, both of our null models support the conclusion that habitat types differ, either shuffling taxa labels $(p=0.002)$ or species occurrence data $(p<0.001)$. For the regional scale, the first PCPS made it possible to distinguish grasslands from forest areas, and also to differentiate clade Magnolianae from Rosanae and Asteranae clades (Fig. 3). In this PCPS, clades Asteranae and Rosanae are represented in all habitat categories, while the basal clade of Magnolinae is only represented in forest areas, whether edge or forest interior (Fig. 3, Fig. 1 in Appendix 1). Regarding PCPS 2, we found significant differences only between grasslands and forest interior $(\mathrm{F}=6.449, \mathrm{p}=0.022)$, and in this case, 
our null model in which the taxa labels are shuffled across the phylogenetic tree did not show significant results $(\mathrm{p}=$ 0.325 ), while the randomization of the community data showed a significant difference among habitat types $(p=0.015)$. PCPS 2 splits species from the Asteranae clade from those from Rosanae; furthermore, Rosanae species show a higher dispersion along PCPS 2 than Asteranae species; by its turn, Magnolidae species show scores around the axis origin, as most dispersion for Magnolidae species is represented along the first PCPS. Although ANOVA shows differences between grasslands and forest interior in relation to PCPS 2 scores, the association between habitats and clades is not clear (Fig. 3, Fig. 1 in Appendix 1).

For the site scale, the fraction of total phylogenetic composition in the plots synthesized in the two first PCPS varied across different sites, ranging from $26.91 \%$ to $46.02 \%$. At the local scale, the fraction of total phylogenetic composition in the plots synthesized in the two first PCPS varied across different sites, ranging the two first PCPS explained from
$25.07 \%$ to $49.61 \%$ (Table 2 in Appendix 1). According to the metanalysis, ANOVAs performed for both for site and local scales showed significant patterns of variation among habitat categories for the two first PCPS (Table 2). Furthermore, metanalysis indicated that congruence values of Procrustes adjustment (Table 3 in Appendix 1) were significant at both spatial scales, with mean correlation among areas of 0.83 for site scale and of 0.87 among sites for local scale (Table 2). That is to say, the association between major clades and habitat categories found at the regional scales also occurred at site and local scales.

\section{Discussion}

In this study, we found consistent patterns of phylogenetic composition in sites with different species composition. All sites had a similar pattern of association among the main phylogenetic clades and habitat categories, regardless of prevailing phytogeographic region and species composition in

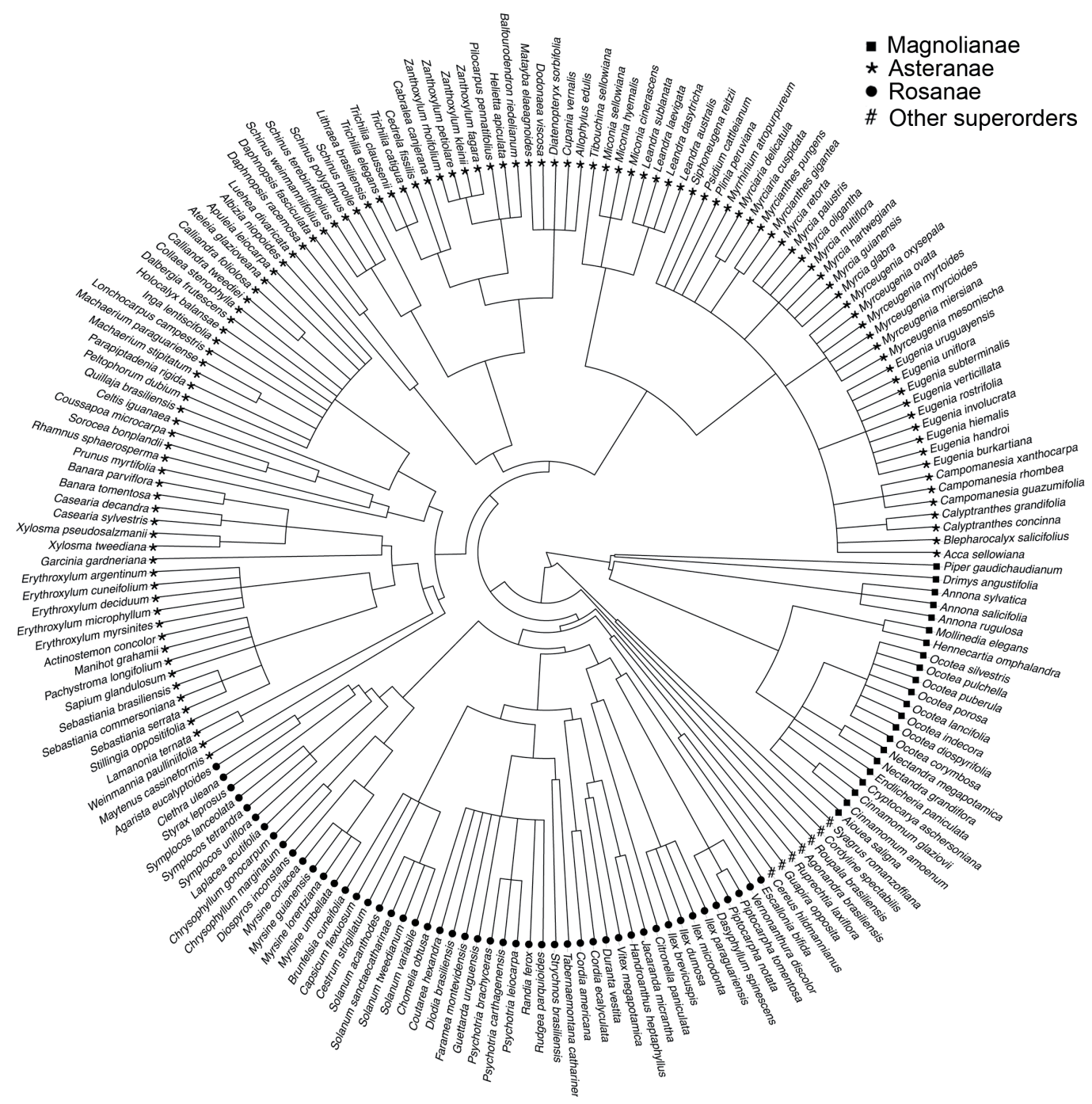

Figure 2. Phylogenetic relations for the species pool occurring in ecotones composed by grasslands and forests in Southern Brazil. The phylogenetic tree follows the phylogenetic hypothesis proposed by Soltis et al. (2011). Symbols in terminal branches represent the superorders to which the species belong. 

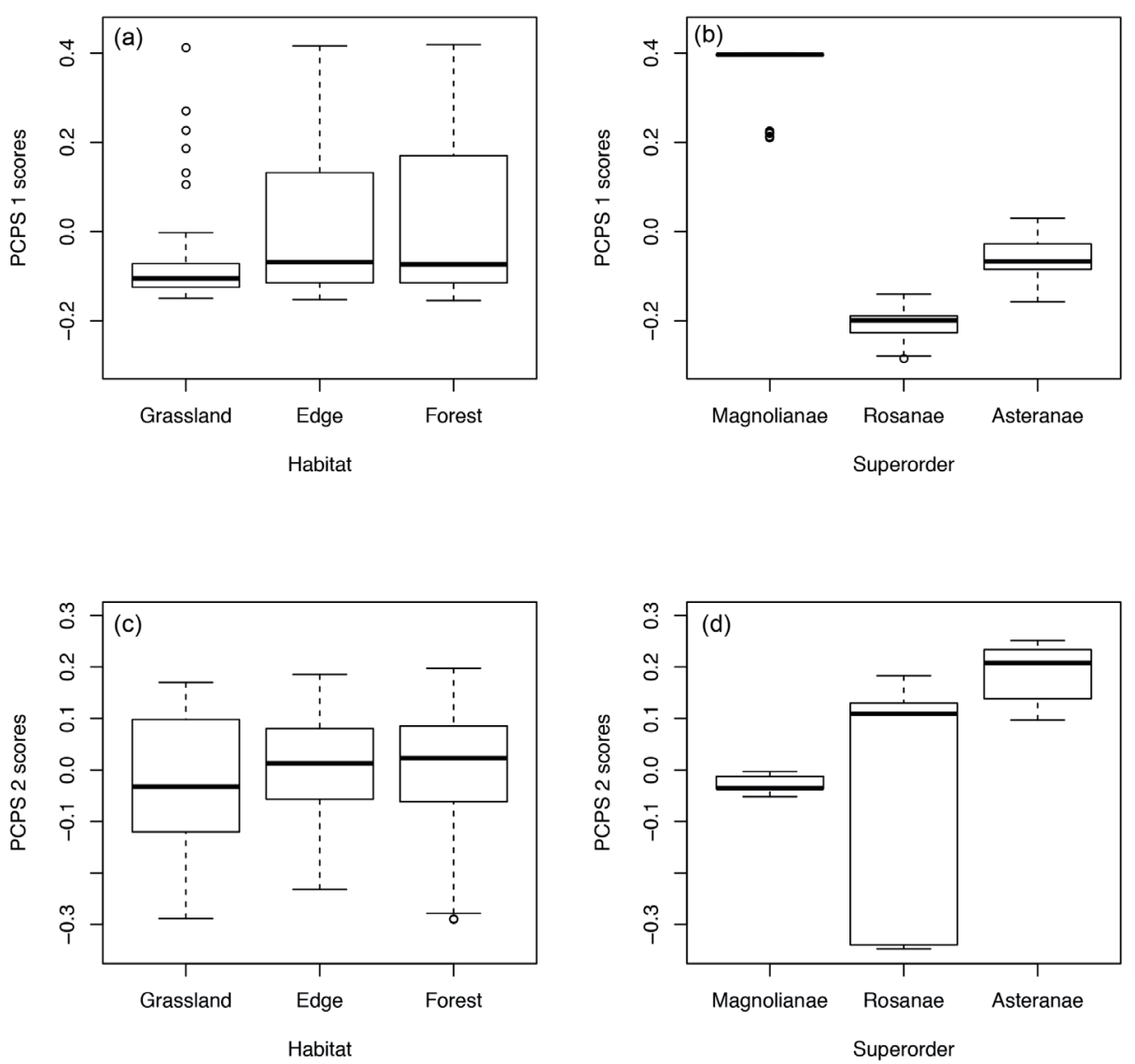

Figure 3. Standard boxwhisker-plots for the first two PCPS computed considering the regional species pool. (a) and (c) - Scores of PCPS 1 and 2, respectively, for plots distributed among the three habitat categories. (b) and (d) - projection of Superorders Magnolianae, Rosanae and Asteranae on scores of PCPS 1 and PCPS 2, respectively. Scores of PCPS 1 show differences between grasslands, edges and forest interior, while scores of PCPS 2 show differences only between grasslands and forest interior. Scatter diagrams with the two first PCPS in each site and scale of analysis are shown in Fig. 1 of Appendix 1. the sampled site (Table 2, Table 3 in Appendix 1). Association patterns between phylogenetic clades and some types of habitats are not new in the literature (Swenson et al. 2006, Willis et al. 2010, Duarte 2011, Kooyman et al. 2011), but in this study we observed that the clade-habitat relationships were recurrent across different vegetation types, regardless of the phylogenetic pool size used to evaluate that association. Basal clades (Magnolianae) were associated with forest areas, while clades of more recent diversification (Rosanae and Asteranae) tended to represent the forefront of forest expansion processes over grasslands in different phytogeographic regions in Southern Brazil (Fig. 3). These results suggest that grasslands act as habitat phylogenetic filters for clades of forest woody species. In other words, grassland-forest boundaries affect differently the distribution of distinct angiosperm clades in ecotones (Duarte 2011). Therefore, the distribution of forest vegetation in contact areas between forest and grasslands show high predictability, at least at a regional scale, generating generalizable patterns of vegetation distribution, which is not observed when we considered only species composition.

The association between phylogenetic clades and different habitat types observed in this study may be reflecting in part the evolutionary trajectory of angiosperms (Feild et al. 2004). Evidence suggests that angiosperms have originated in the humid and shaded understory of gymnosperm- and pteridophyte-dominated forests, and that during the evolutionary process they started occupying more open areas with lower water availability. Here we found that species of Magnolianae superorder occurring in the ecotones were limited to forest interior areas. This pattern likely reflects their lower efficiency in water use and photosynthetic capacity when compared to other angiosperms of more recent diversification (Boyce et al. 2009, Brodribb and Feild 2010). Basal angiosperms, such as Magnolianae, have a tendency to have lower density of leaf veins (Boyce et al. 2009), low capacity of gas exchange (Feild et al. 2011) and low photosynthetic capacity (Brodribb and Feild 2010), when compared to angiosperms of more recent diversification as Rosanae and Asteranae. Such characteristics of basal clades may probably confer plants tolerance to drought, since mechanisms to avoid water loss in environments of high rates of evapotranspiration are less efficient. These ecophysiological differences could reduce the tolerance of basal clades in less shaded environments, with lower hydric availability. In clades of more recent diversification, this restriction apparently does not occur in all species, which allows species to be distributed across different habitats types. Higher photosynthetic rates and more efficiency in resources use allow plants to increase carbon availability for growing and consequently greater competitive performance to deal with direct competition with species from grasslands (Scholes and Archer 1997). As some species establish themselves in grasslands, they cause some changes in microenvironmental conditions, allowing species from basal clades to get established, as well, increasing forest distribution bounds (Valiente-Banuet et al. 2006). 
Table 2. Values of the metanalysis for Procrustes adjustment and for the F values of ANOVA at site and local scale. Summary of effect between areas and sites based on the random model of DerSimonian-Laird. See text for more details.

\begin{tabular}{llccc}
\hline Scale & Original statistic & $\begin{array}{c}\text { Average } \\
\text { effect size }\end{array}$ & $\begin{array}{c}\text { Fisher's } \\
\text { Z }\end{array}$ & $\mathrm{p}$ \\
\hline Site & $\begin{array}{l}\text { Procrustes statistic } \\
\left(s^{2}\right)\end{array}$ & 0.825 & 2.387 & 0.017 \\
& F-value for PCPS1 & 0.345 & 2.640 & 0.008 \\
& F-value for PCPS2 & 0.184 & 3.510 & $<0.001$ \\
Local & $\begin{array}{l}\text { Procrustes statistic } \\
\left(s^{2}\right)\end{array}$ & 0.866 & 7.567 & $<0.001$ \\
& F-value for PCPS1 & 0.284 & 4.646 & $<0.001$ \\
& F-value for PCPS2 & 0.292 & 6.479 & $<0.001$ \\
\hline
\end{tabular}

The results from this study contradict the prediction of functional equivalence among species of the neutral theory (Hubbel 2001). Different clades tend to occupy the same habitat types in different regions (Parmentier and Hardy 2009, Crisp et al. 2009). Early-successional species, which are able to establish in open environments, should express traits that assign them high dispersion ability, high growth rate, capacity of competition with grass species, besides capacity of survival in a shaded and drier environment, when compared to forest interior. Species that are able to colonize grasslands tend to concentrate in phylogenetic lineages of more recent diversification (Boyce et al. 2009). This differential distribution of clades in distinct habitats suggests some degree of phylogenetic niche conservation in species occurring in ecotones composed by grasslands and forests, although we have not assessed phylogenetic signal in species traits. Accordingly, closely related species would tend to demand similar ecological requirements. Considering that the set of all traits of a species is not independent from the degree of relationship between this and other phylogenetically related species (Wiens and Graham 2005), it is probable that at least some fundamental traits for colonization in grasslands are phylogenetically conserved, although we did not test this hypothesis.

In this study, we used phylogenetic information in order to understand the ecological patterns of grassland-forest ecotones in Southern Brazil, and found evidence that the phylogenetic structure patterns are recurrent across spatial scales. This finding shows that Magnolianae species were associated with forest areas, while Rosanae and Asteranae species are better colonizer of grasslands. Rosanae and Asteranae species form the forefront of grassland colonization by woody plants, likely because they capture resources more efficiently when compared with Magnolianae species, which likely grant some advantage to the former to outcompete grassland species. Understanding the organization patterns of these ecological communities is a first step to comprehend mechanisms that structure them. The search for consistent and recurrent patterns has been a hard work among ecologists. The search for general organization patterns of ecological communities from their phylogenetic structure represents a possibility to relate different determinant factors of ecological community struc- turing, such as niche, dispersion and history (Cavender-Bares et al. 2009). The use of evolutionary information may be an important tool to help us to understand and predict functional patterns of ecological systems, independent of their species identity, increasing our ability to make generalization for real communities.

Acknowledgements. This study had logistic support from the Post-graduate Program in Ecology of Universidade Federal do Rio Grande do Sul and of the São Francisco de Paula National Forest. VJD received a graduate fellowship from Coordenação de Aperfeiçoamento de Pessoal de Nível Superior (CAPES). LDSD received a fellowship from the Brazilian Research Council - CNPq (grant 303534/2012-5).

\section{References}

Anderson, M.J. 2001. A new method for non-parametric multivariate analysis of variance. Austral. Ecol 26: 32-46.

APG. 2009. An update of the Angiosperm Phylogeny Group classification for the orders and families of flowering plants: APG III. Bot. J. Linn. Soc. 161: 105-121.

Behling, H. 2002. South and southeast Brazilian grasslands during Late Quaternary times: a synthesis. Palaeogeogr. Palaeocl. 177: 19-27.

Behling, H. and Pillar, V.D. 2007. Late Quaternary vegetation, biodiversity and fire dynamics on the southern Brazilian highland and their implication for conservation and management of modern Araucaria forest and grassland ecosystems. Philos. T. Roy. Soc. $B$ 362: 243-251.

Bell, C.D., Soltis, D.E. and Soltis, P.S. 2010. The age and diversification of the angiosperms re-revisited. Am. J. Bot. 97: 1-8.

Bond, W.J. and Midgley, G.F. 2000. A proposed $\mathrm{CO}_{2}$-controlled mechanism of woody plant invasion in grasslands and savannas. Glob. Change Biol. 6: 865-869.

Borenstein, M., Hedges, L.V., Higgins, J.P.T. and Rothstein, H.R. 2009. Introduction to Meta-analysis. Wiley. Chichester, UK

Boyce, C.K., Brodribb, T.J., Feild, T.S. and Zwieniecki, M.A. 2009. Angiosperm leaf vein evolution was physiologically and environmentally transformative. P. Roy. Soc. Lond. B Biol. 276: 1771-1776.

Brodribb, T.J. and Feild, T.S. 2010. Leaf hydraulic evolution led a surge in leaf photosynthetic capacity during early angiosperm diversification. Ecol. Lett. 13: 175-183.

Burns, J.H. and Strauss, S.Y. 2011. More closely related species are more ecologically similar in an experimental test. P. Natl. Acad. Sci. USA 108: 5302-5307.

Cavender-Bares, J., Kozak, K.H., Fine, P.V.A. and Kembel, S.W. 2009. The merging of community ecology and phylogenetic biology. Ecol. Lett. 12: 693-715.

Crisp, M.D., Arroyo, M.T.K., Cook, L.G., Gandolfo, M.A., Jordan, G.J., McGlone, M.S., Weston, P.H., Westoby,M., Wilf, P. and Linder, H.P. 2009. Phylogenetic biome conservatism on a global scale. Nature 458: 754-756.

Darwin, C. 1859. On the Origin of Species by Means of Natural Selection, or the Preservation of Favoured Races in the Struggle for Life. J. Murray. London, UK.

Diamond, J.H. 1975. Assembly of species communities. In: Cody M.L. and Diamond, J.H. (eds), Ecology and Evolution of Communities. Belknap Press. Cambridge, US. pp. 342-444. 
Donoghue, M.J. 2008. A phylogenetic perspective on the distribution of plant diversity. P. Natl. Acad. Sci. USA 105: 11549-11555.

Duarte, L.D.S. 2011. Phylogenetic habitat filtering influences forest nucleation in grasslands. Oikos 120: 208-215.

Duarte, L.D.S., Carlucci, M.B., Hartz , S.M. and Pillar, V.D. 2007. Plant dispersal strategies and the colonization of Araucaria forest patches in a grassland-forest mosaic. J. Veg. Sci. 18: 847-858.

Feild, T.S., Arens, N.C., Doyle, J.A., Dawson, T.E. and Donoghue, M.J. 2004. Dark and disturbed: a new image of early angiosperm ecology. Paleobiology 30: 82-107.

Feild, T.S., Upchurch Jr., G.R., Chatelet, D.S., Brodribb, T.J., Grubbse, K.C., Samain, M. and Wanke, S. 2011. Fossil evidence for low gas exchange capacities for Early Cretaceous angiosperm leaves. Paleobiology 37: 195-213.

Felsenstein, J. 1985. Phylogenies and the comparative method. Am Nat. 125: 1-15.

Gotelli, N.J. and Entsminger, G.L. 2001. Swap and fill algorithms in null model analysis: rethinking the knight's tour. Oecologia 129: 281-291.

Harper, K.A., Macdonald, S.E., Burton, P.J., Chen, J., Brosofske, K.D., Saunders, S.C., Euskirchen, E.S., Roberts, D., Jaiteh, M.S and Esseem, P. 2005. Edge influence on forest structure and composition in fragmented landscapes. Conserv. Biol. 19: 768-782.

Hubbell, S. 2001. The Unified Neutral Theory of Biodiversity and Biogeography. Princeton University Press. Princeton, US.

IBGE. 1986. Levantamento dos Recursos Naturais, Projeto Radam Brasil. Volume 33. IBGE. Rio de Janeiro, BR.

Jackson, D.A. 1995. PROTEST: A Procrustean randomization test of community environment concordance. Écoscience 2: 297-303.

Kapos, V. 1989. Effects of isolation on the water status of forest patches in the Brazilian Amazon. J. Trop. Ecol. 5: 173-185.

Keddy, P. and Weiher, E. 1999. Introduction: The scope and goals of research on assembly rules. In : Weiher, E. and Keddy, P. (Eds.), Ecological Assembly Rules: Perspectives, Advances, Retreats. Cambridge University Press. Cambridge, UK. pp. 1-20.

Kembel, S.W. and Hubbell, S. P. 2006. The phylogenetic structure of a neotropical forest tree community. Ecology 87: 86-99.

Kooyman, R., Rossetto, M., Cornwell, W. and Westoby, M. 2011. Phylogenetic tests of community assembly across regional to continental scales in tropical and subtropical rain forests. Global Ecol. Biogeogr. 20: 707-716

Laurance, W.F., Lovejoy, T.E., Vasconcelos, H.L., Bruna, E.M., Didham, R.K., Stouffer, P.C., Gascon, C., Bierregaard, R.O., Laurance, S.G. and Sampaio, E. 2002. Ecosystem decay of Amazonian forest fragments: a 22-year investigation. Conserv. Biol. 16: 605-618.

Laurance, W.F, Nascimento, H.E.M., Laurance, S.G., Andrade, A.C.S., Ribeiro, J.E.L.S., Giraldo, J.P., Lovejoy, T.E., Condit, R.S., Chave, J., Harms, K.E. and D'Angelo, S.A. 2006. Rapid decay of tree-community composition in Amazonian forest fragments. P. Natl. Acad. Sci. USA 103: 19010-19014.

Legendre, P. and Legendre, L. 1998. Numerical Ecology. Elsevier. Amsterdam, NL.

Leite, P.F. 2002. Contribuição ao conhecimento fitoecológico do sul do Brasil. Ciência \& Ambiente 24: 51-73.

Letcher, S.G. 2010. Phylogenetic structure of angiosperm communities during tropical forest succession. P. Roy. Soc. Lond. B Biol. 277: 97-104

Matlack, G.R. 1994. Vegetation dynamics of the forest edge trends in space and successional time. J. Ecol. 88: 113-123.
Müller, S.C., Overbeck, G.E., Pfadenhauer, J. and Pillar, V.D. 2012. Woody species patterns at forest-grassland boundaries in southern Brazil. Flora 207: 586-598.

Oliveira, J. M. and Pillar, V. D. 2004. Vegetation dynamics on mosaics of Campos and Araucaria forest between 1974 and 1999 in Southern Brazil. Community. Ecol. 5: 197-202.

Parmentier, I. and Hardy, O.J. 2009. The impact of ecological differentiation and dispersal limitation on species turnover and phylogenetic structure of inselberg's plant communities. Ecography 32: 613-622

Pillar, V.D. and Duarte, L.S. 2010. A framework for metacommunity analysis of phylogenetic structure. Ecol. Lett. 13: 587-596.

Rambo, B. 1956. A fisionomia do Rio Grande do Sul. 2nd ed. Selbach. Porto Alegre, BR.

Ricklefs, R.E. 1987. Community diversity: relative roles of local and regional processes. Science. 235: 167-171.

Ries, L. Fletcher, R.J.J., Battin, J. and Sisk, T.D. 2004. Ecological responses to habitat edges: Mechanisms, models, and variability explained. Аnпи. Rev. Ecol. Syst. 35: 491-522.

Santos, B.A., Arroyo-Rodríguez, V., Moreno, C.E. and Tabarelli, M. 2010. Edge-related loss of tree phylogenetic diversity in the severely fragmented Brazilian atlantic forest. PloS one 5: e12625.

Scholes, R.J. and Archer, S.R. 1997. Tree-grass interactions in savannas. Annu. Rev. Ecol. Syst. 28: 517-544.

Sokal, R.R. and Rohlf, F.J. 1994. Biometry. W.H. Freeman and Co. New York, US

Soltis, D.E., Smith, S.A., Cellinese, N. et al. 2011. Angiosperm phylogeny: 17 genes, 640 taxa. Am. J. Bot. 98: 704-730.

Swenson, N.G., Enquist, B.J., Pither, J., Thompson, J. and Zimmerman, J.K. 2006. The problem and promise of scale dependency in community phylogenetics. Ecology 87: 2418-2424.

Valiente-Banuet, A., Rumebe, A.V., Verdú, M. and Callaway, R.M. 2006. Modern Quaternary plant lineages promote diversity through facilitation of ancient Tertiary lineages. P. Natl. Acad. Sci. USA 103: 16812-16817.

Webb, C.O., Ackerly, D.D., McPeek, M.A. and Donoghue, M.J. 2002. Phylogenies and community ecology. Annu. Rev. Ecol. Syst. 33: 475-505.

Wiens, J.J. and Graham, C.H. 2005. Niche conservatism: Integrating evolution, ecology, and conservation biology. Annu. Rev. Ecol. Syst. 36: 519-539.

Willis, C.G., Halina, M., Lehman, C., Reich, P.B., Keen, A., McCarthy, S. and Cavender-Bares, J. 2010. Phylogenetic community structure in Minnesota oak savanna is influenced by spatial extent and environmental variation. Ecography 33: 565-577

Received September 13, 2013

Revised February 3, May 7, 2014 Accepted June 17, 2014

\section{Electronic supplements}

Appendix 1. Supplementary statistical results.

Appendix 2. Species sampled and their presence in each analyzed site.

The file may be downloaded from www.akademiai.com. 